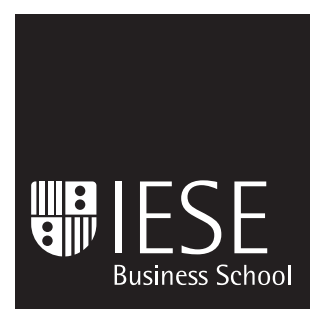

Working Paper

WP no 620

CIIF

March, 2006

University of Navarra

\title{
STUDY OF THE DOLLAR-EURO EXCHANGE RATE
}

\author{
Miguel A. Ariño \\ Miguel A. Canela
}


The CIIF, International Center for Financial Research, is an interdisciplinary center with an international outlook and a focus on teaching and research in finance. It was created at the beginning of 1992 to channel the financial research interests of a multidisciplinary group of professors at IESE Business School and has established itself as a nucleus of study within the School's activities.

Ten years on, our chief objectives remain the same:

- Find answers to the questions that confront the owners and managers of finance companies and the financial directors of all kinds of companies in the performance of their duties

- Develop new tools for financial management

- Study in depth the changes that occur in the market and their effects on the financial dimension of business activity

All of these activities are programmed and carried out with the support of our sponsoring companies. Apart from providing vital financial assistance, our sponsors also help to define the Center's research projects, ensuring their practical relevance.

The companies in question, to which we reiterate our thanks, are:

Aena, A.T. Kearney, Caja Madrid, Fundación Ramón Areces, Grupo Endesa, Royal Bank of Scotland and Unión Fenosa.

http://www.iese.edu/ciif/ 


\title{
STUDY OF THE DOLLAR-EURO EXCHANGE RATE
}

\author{
Miguel A. Ariño* \\ Miguel A. Canela**
}

\section{Abstract}

In this paper we broadly describe the changes in the dollar-euro exchange rate from the time the euro came into effect at the beginning of 1999 until the end of 2005, using daily data. We show how movements in this exchange rate can be presented in different ways, depending on the time scale we use.

First, if we focus on periods of more than six months, the changes in the dollar-euro rate can be described using a succession of linear trends. Superimposed on this trend line are cycles lasting from one to three months. Lastly, on a daily scale, the exchange rate behavior is virtually unpredictable, very close to what econometricians call white noise.

These patterns are not exclusive to the dollar-euro rate, but are shared by the dollar exchange rates of most free-floating currencies. Taking the exchange value of the dollar against a basket of currencies used by the Federal Reserve, we show that the patterns we observe may be attributed to changes in the "intrinsic" value of the dollar.

* Professor of Managerial Economics, IESE

** Professor of the University of Barcelona

Keywords: Exchange rate, volatility, trade weighted exchange index, random walk 


\section{STUDY OF THE DOLLAR-EURO EXCHANGE RATE}

\section{Introduction}

In the abundant literature on exchange rates we can identify two distinct approaches. On the one hand, there is the macroeconomic approach, which seeks to relate exchange rate changes to monetary variables (monetary fundamentals), such as monetary aggregates or indices reflecting national income. Studies adopting this approach use monthly data. For exchange rates, this means the exchange rate value on the last day of the month. And for the fundamentals, monthly figures are extracted from the monetary aggregates (M1, M2 or M3) and indices of industrial production. These indices are used as a substitute for GDP, which is calculated quarterly.

Findings regarding the possibility of predicting exchange rate movements from fundamentals have been negative. In a widely cited article, Meese and Rogoff (1983) showed that exchange rate forecasts based on fundamentals were no better than those based on a simple random walk model (see details below). Meese and Rogoff's findings had a devastating effect at the time and sparked a host of studies aimed at verifying the robustness of the authors' method. A review of this and other exchange rate issues can be found in Sarno (2005).

Sarno suggests other ways of approaching the problem and points to two explanations for the disappointing results obtained so far. One is that the studies carried out to date confine themselves to classic econometric forecasting methods, based essentially on linear regression. The other is that they use only publicly available information, while private information, such as information about investor decisions, is key to explaining exchange rate behavior. Taking a different line, Andersen et al. (2002) tested the influence of breaking macroeconomic news on exchange rate movements over the course of the day.

Other authors have studied exchange rate movements from a different angle. Instead of creating a model to predict the value of the exchange rate from other variables, they have chosen a model from among those commonly used in time series analysis. One of the advantages of this approach is that we can try out multivariate models, involving several exchange rates, and explore interdependencies through correlations or similar measures. Another advantage is that, as we are not bound by the fact that the monetary variables to which we want to relate the exchange rate are calculated monthly (or, in the case of GDP, quarterly), we can create models for daily (or even intraday) exchange rate movements.

However, these studies are of theoretical interest only and do not help to predict future exchange rate movements. Establishing the relationship between two variables may allow us to deduce that a particular coefficient of an equation is significant, but the equations thus obtained are of little practical use. For example, Ehrmann et al. (2005) propose a structural 
model for transmission between the daily returns of stocks, bonds, interest rates and exchange rates, citing evidence that such transmission actually takes place. But the model can only be applied in retrospect, when all the daily data is available.

Among the univariate models, the simplest is the random walk, which makes very simple predictions. In most cases, the random walk model is applied to the log of the exchange rate. Hence, if $x(t)$ is the exchange rate in period $t$, the change in the log of the exchange rate with respect to the previous period is the so-called log return, which will be white noise (that is, there is no correlation between the present value and the past value). Despite involving a log transformation, this return can be interpreted directly, as we can take it as an approximation to the proportion in which the rate has changed with respect to the previous period. That is:

$$
r(t)=\nabla \log x(t)=\log (x(t) / x(t-1)) \approx \frac{x(t)-x(t-1)}{x(t-1)}
$$

Note that the validity of the random walk model is not to be considered in the abstract, but in the context of particular exchange rates and always specifying the frequency with which the exchange rate is measured. Guo and Savickas (2005), for example, argue that the random walk model is not valid for exchange rates; yet they use only quarterly data. Shorter-term fluctuations, and in particular the daily changes that are the main subject of this paper, are a very different matter.

In this study we look at euro-U.S. dollar exchange rate movements from the effective adoption of the euro, at the beginning of 1999, until the end of 2005. The data used in this paper $(n=$ 1756) are taken from the US/Euro Foreign Exchange Rate, as published by the Board of Governors of the Federal Reserve System (buying rates in New York City for cable transfers payable in foreign currencies). The data have been taken from the Federal Reserve Bank of Saint Louis's public access database (FRED).

Whereas other studies with a macroeconomic orientation examine series covering much longer periods and reconstruct euro rates prior to 1999 from the rates for the German mark, this study has a financial orientation and focuses on short-term expectations.

We pay special attention to two issues of great interest in exchange rate research: turning points and volatility. Here, we use a simple non-parametric method to establish the trend. Changes are identified using a very popular method, introduced in a now classic work by Bry and Boschan (1971), which has been widely used to identify cycles in macroeconomic series (business cycles).

Exchange rate volatility may be measured in a variety of ways. Here, we adopt the direct method, which uses the actual series of exchange rate values to obtain a volatility estimate, using conventional time series analysis techniques. Another method, using the prices of exchange rate options, is based on the Black-Scholes formula, assuming that the observed values come from the sampling of a continuous process (implied volatility). More recently, other methods using dispersion measures of intraday exchange rate values as a measure of volatility (realized volatility) have gained popularity. Andersen et al. (2005) provides a fairly complete review of methods for measuring volatility. We prefer the direct method because it is the one most used by finance professionals and because we did not want to get involved in analyzing intraday exchange rate movements.

In examining the various issues covered in this report, we repeatedly compare the dollar/euro rate with other exchange rates, all against the dollar, in order to clarify which of the traits we 
observe are specific to the rate we are studying. The data for these rates come from the same source as those for the dollar/euro rate. Some of them, such as the Swiss franc/dollar rate, we have inverted so that they all have the dollar in the numerator, making them more readily comparable.

\section{Long dollar/euro rate cycles}

Figure 1 shows dollar/euro exchange rate movements from January 4, 1999 to December 23, 2005. We see the exchange rate fall from a starting value of 1,181 to a low point of 0.827 on October 25, 2000, then rise more or less continuously from February 2002 to a peak of 1.362 on December 30, 2004. From there it declines to a level just below 1.19, at the end of 2005. Taking as a reference the mid-point between the minimum and the maximum, we can say that the total change is $\pm 27 \%$, which gives an idea of how important an issue this is for investors.

\section{Figure 1}

Dollar/euro exchange rate

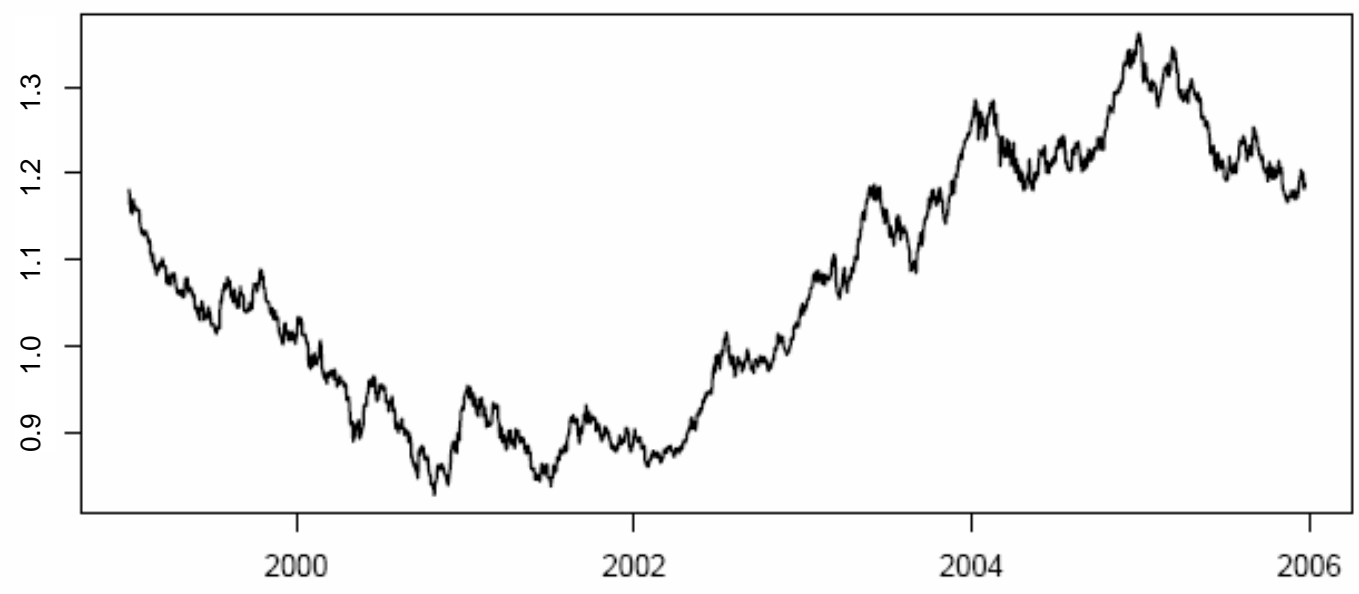

Figure 1 suggests that changes in the dollar/euro rate may be seen to follow different patterns, depending from what perspective we examine them. First, if we focus on the long term, that is to say, changes whose effect persists for one quarter or more, we see four periods, or long cycles, which in Figure 2 we have highlighted by superimposing onto Figure 1 a trend line showing the long-term changes.

The trend line in Figure 2 has been obtained by what in econometrics is called smoothing with a Gaussian core. More specifically, each value of the trend, or smoothed series, is a weighted average of values of the dollar/euro rate, in which the weights follow the profile of a bell curve whose breadth can be adjusted according to the degree of smoothing desired. The parameter that regulates this effect is called "bandwidth". In Figure 2 we have used a bandwidth of 40 days, which eliminates fluctuations whose amplitude is less than four months. 


\section{Figure 2}

Dollar/euro exchange rate, with trend line



We now have a curve in which we can clearly distinguish four periods: an initial decline from January 1999 until the second quarter of 2000; a period of around nine months in which the rate is stable at around 0.9 (with shorter oscillations); a more than two-year-long period of euro appreciation, with an increase of around 0.4 dollars/euro; and a final period of dollar recovery, which is the period we are in now, ending at a level slightly higher than at the start of 1999.

The turning points have been determined by the Bry-Boschan method mentioned earlier (a detailed description is given in Harding and Pay, 2002). This method associates turning points with periods $t_{0}$, where the value of the series reaches a local maximum or minimum; specifically, where either:

$$
x\left(t_{0}\right)=\max \cdot\left\{x(t): t_{0}-k \leq t \leq t_{0}+k\right.
$$

or:

$$
x\left(t_{0}\right)=\min .\left\{x(t): t_{0}-k \leq t \leq t_{0}+k\right.
$$

is met. $k$ is chosen according to the frequency of the series. For the quarterly GNP series to which these ideas were first applied in order to identify business cycles, the researchers used $k=2$, equivalent to half a year. In another, more recent application to commodity prices, McDermott and Scott (2000) used $k=12$ for monthly series. Here, where the data are daily, we have used $k=50$, more or less equivalent to two and a half months, applying the algorithm to the smoothed series.

It does not look as if it is going to make much difference if we replace the curve given by the trend in Figure 2 by the segmented line produced by joining the turning points we have identified with straight-line segments. That is what we have done to produce the trend line shown in Figure 3. Although the fit in the third segment could be improved by increasing the slope of that segment, or by adding a period of stability in 2004 before the start of the decline in 2005 , it is fair to say that the figure already does what we want it to do: show the pattern of change in the dollar/euro rate during this period. 


\section{Figure 3}

Dollar/euro exchange rate, with trend made up of straight-line segments

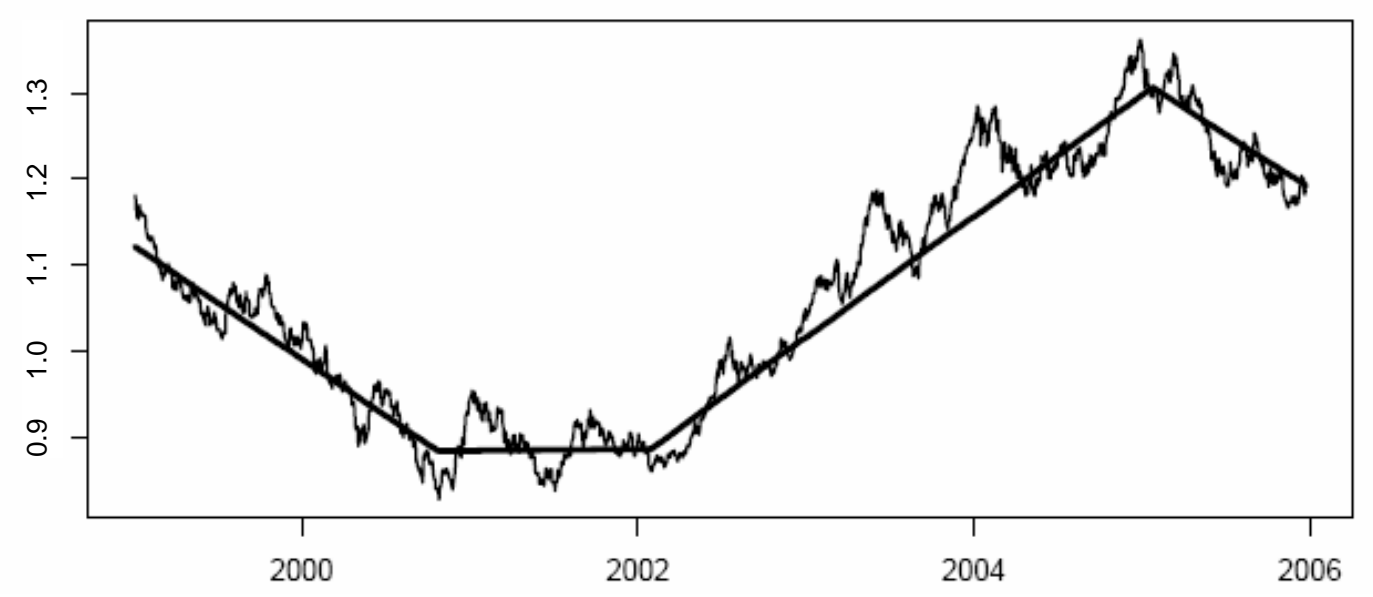

We may ask whether this pattern of change is specific to this particular exchange rate or whether it is also found in other free-floating rates. If the same pattern is found in other freefloating rates, we may attribute it to changes in the "value" of the dollar. Table 1 shows the correlations between a number of exchange rates to illustrate this point. As explained earlier, some rates have been inverted for the sake of comparison. For example, the results given here for the dollar/Swiss franc rate refer to the inverse of the Swiss franc-dollar rate (francs per dollar) published by the Federal Reserve.

As a benchmark, we have included the Trade Weighted Exchange Index (TWEI), which is a weighted average of the exchange values of the dollar against the currencies of a broad group of U.S. trading partners, published by the St. Louis Federal Reserve Bank. In this index, the value of the dollar in January 1997 has been set equal to 100. In this study, we use the TWEI as a proxy for the intrinsic value of the dollar.

\section{Table 1}

Correlation between different exchange rates

\begin{tabular}{|c|c|c|c|c|c|c|c|c|}
\hline & USD/GBP & USD/CHF & USD/CAD & USD/MXP & USD/SAR & USD/JPY & USD/AUD & TWEI \\
\hline USD/EUR & 0.969 & 0.979 & 0.864 & -0.885 & 0.636 & 0.520 & 0.947 & -0.865 \\
\hline USD/GBP & & 0.941 & 0.866 & -0.847 & 0.673 & 0.615 & 0.954 & -0.891 \\
\hline USD/CHF & & & 0.835 & -0.923 & 0.489 & 0.428 & 0.888 & -0.766 \\
\hline USD/CAD & & & & -0.766 & 0.625 & 0.548 & 0.915 & -0.862 \\
\hline USD/MXP & & & & & -0.401 & -0.428 & -0.785 & 0.644 \\
\hline USD/SAR & & & & & & 0.751 & 0.741 & -0.882 \\
\hline USD/JPY & & & & & & & 0.622 & -0.765 \\
\hline USD/AUD & & & & & & & & -0.941 \\
\hline
\end{tabular}

The sign of the correlations in the table is as expected, apart from the Mexican peso, which is an exception studied in detail in a recent work (Canela and Pedreira, 2006). Aside from the peso, we can see that the correlation is very strong in the case of the European currencies and the Australian dollar, somewhat weaker in the case of the Canadian dollar, and weaker still in that of the South African rand and the Japanese yen. These patterns hold if, in the first group, 
we include other European currencies such as the Swedish krona or the Danish or Norwegian krone, or the New Zealand dollar; or if we consider other Asian currencies such as the Korean won, the Taiwan dollar or the Indian rupee.

At the same time, disregarding the Mexican peso, the correlations with the TWEI are strong. This shows that most of the changes in the free-floating rates may be attributed to changes in the general value of the dollar. In Figure 4 we show the changes in the TWEI in the period under study, with a trend line obtained by the same procedure as in Figure 2.

The curve given by the trend line in Figure 4 is largely an (inverted) mirror image of the one in Figure 2, especially from early 2002 onward. This similarity can be attributed partly to the fact that the basket of currencies used to prepare the TWEI is dominated by the euro. To determine the extent to which changes in any of these exchange rates can be attributed to the strength or weakness of the dollar, we use the TWEI to obtain proxies of the exchange value of the other currencies (against the currencies used to calculate the TWEI), on a scale referenced to the exchange value of the dollar in 1997.

\section{Figure 4}

Trade Weighted Exchange Index

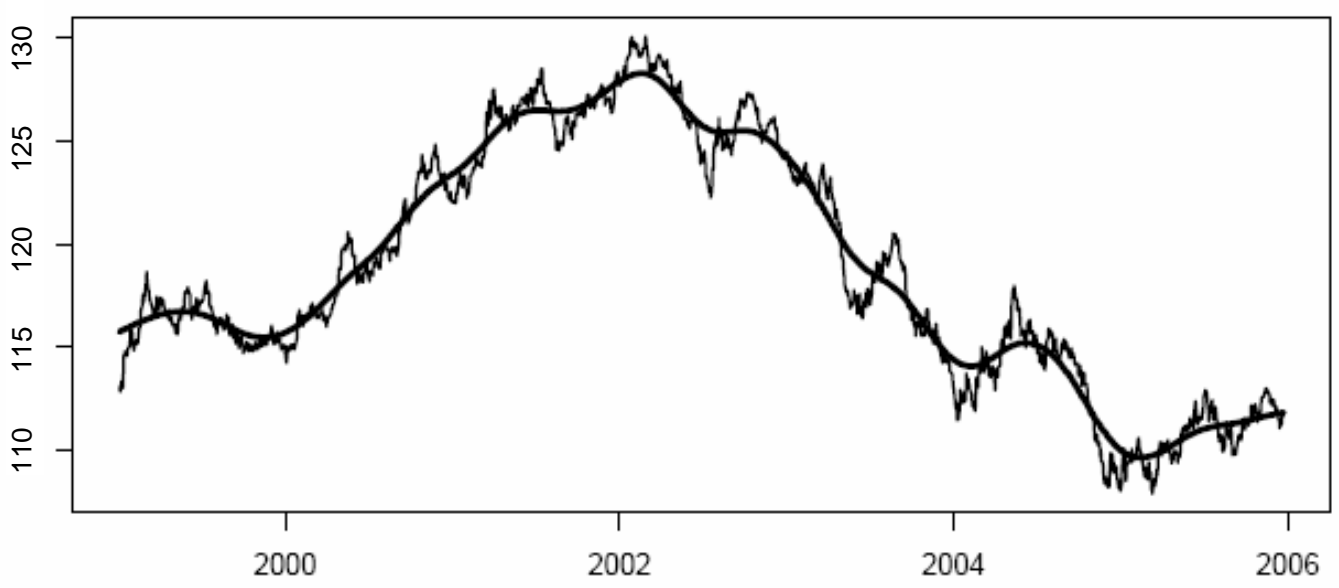

Multiplying the exchange rate by the TWEI, we obtain an index in which the value 100 corresponds to the exchange value of the dollar in January 1997. In this study, this index is used as a proxy for a currency's intrinsic exchange value. The less weight a currency has in the basket on which the TWEI is based, the more valid this proxy will be.

Figure 5 shows the changes in the exchange value of the euro. By way of contrast, Figure 6 shows the changes in the exchange value of the yen. While the patterns in Figure 5 are similar to those of Figures 2 and 4 (inverted), the pattern in Figure 6 is different. In Figure 6, the trend of the yen is, in part of the graph, opposite to that of the euro. 


\section{Figure 5}

Intrinsic exchange value of the euro

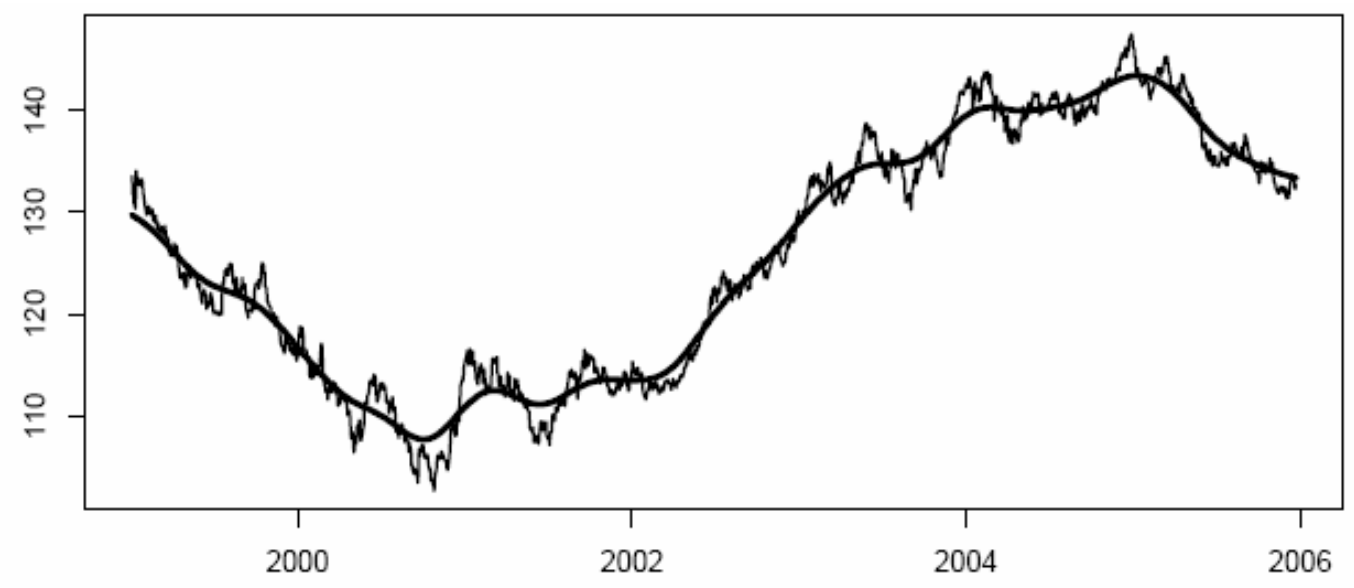

\section{Figure 6}

Intrinsic exchange value of the yen



It is interesting to compare the correlations between the proxies we have constructed and those in Table 1. This is done in Table 2, which shows the correlations of the euro with the other currencies shown in Table 1. Most striking are the correlations of the British pound, the Swiss franc and the Australian dollar, whose intrinsic value seems strongly linked to that of the euro. The same is the case with other European currencies and the New Zealand dollar (not included in the table). With the Canadian dollar the correlation is weaker, and even weaker with the rand. In contrast, with the yen (and with the other Asian currencies) we find a negative correlation. As we said earlier, the correlation of the Mexican peso deserves to be treated separately.

\section{Table 2}

Correlation between the intrinsic value of the euro and that of other currencies

\begin{tabular}{ccccccc}
\hline GBP & CHF & CAD & MXP & SAR & JPY & AUD \\
\hline 0.923 & 0.955 & 0.662 & -0.921 & 0.332 & -0.282 & 0.887 \\
\hline
\end{tabular}




\section{Short cycles of the dollar/euro rate}

In this section we shall look at the short cycle of the dollar/euro rate, which is described by a trend line reflecting fluctuations over shorter periods than those observed in the previous section. Again we use the same method as in Figure 2, with a narrower band. In light of Figure 2, which shows fluctuations around the trend curve of between one and three months' duration, a bandwidth of ten days seems appropriate. The result, restricted to two years for easier visibility, can be seen in Figure 7.

\section{Figure 7}

Dollar/euro exchange rate

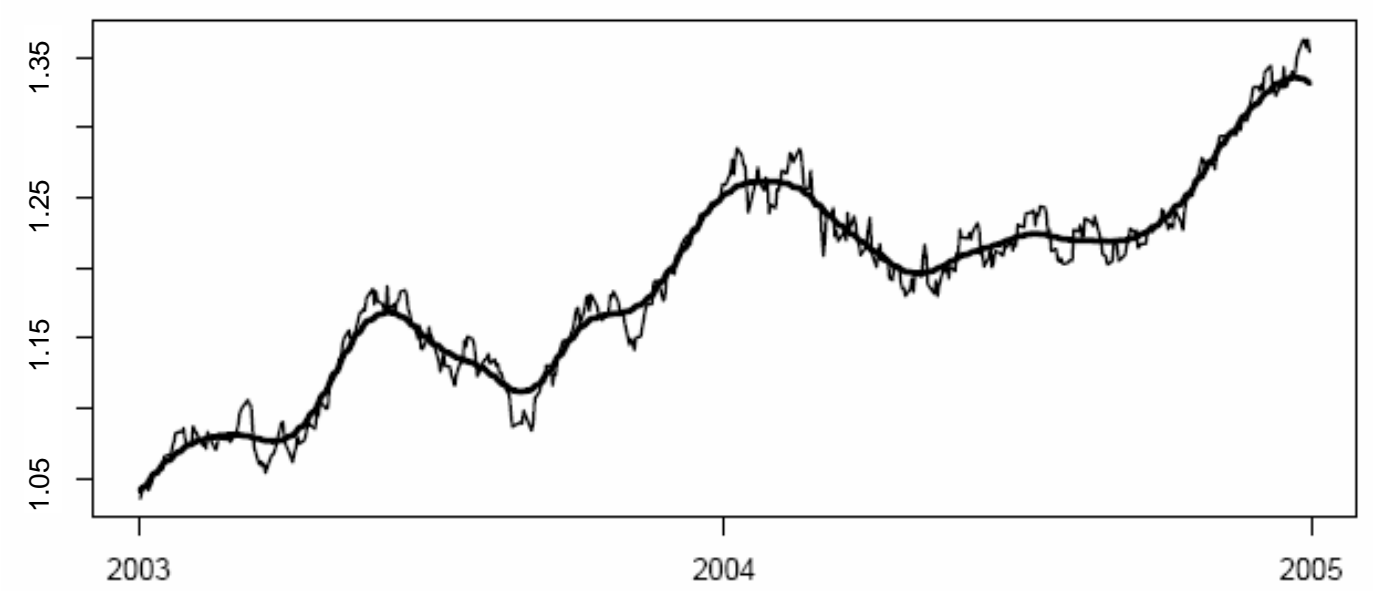

To more easily apprehend the long cycle of the dollar/euro rate, it is shown by a segmented line made up of successive appreciation and depreciation trends, articulated by three turning points. With the data available to us we can go no further than this. To characterize the short cycle we adopt a different point of view. First we prepare a new series made up of the deviations with respect to the long cycle, discounting the Figure 2 trend from the dollar/euro rate. We shall now examine this series, which is shown in Figure 8 for the same period as in Figure 7.

\section{Figure 8}

Deviations from the long cycle in the dollar/euro rate, 2003-2004

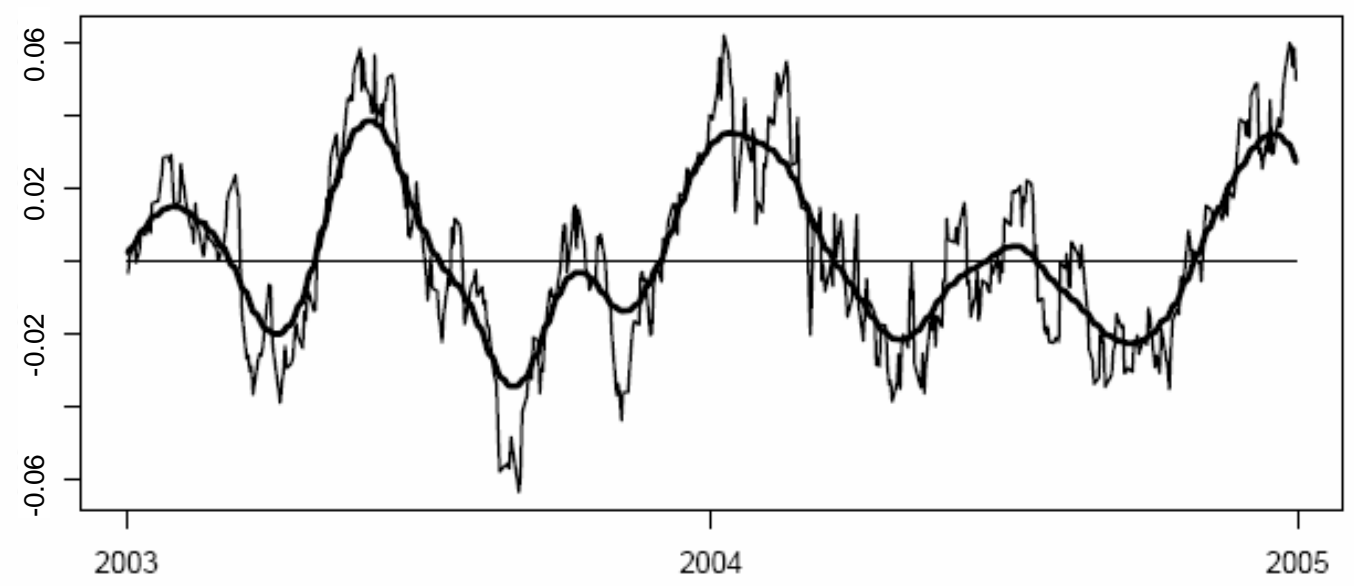


The Figure 8 series shows a very strong positive autocorrelation (correlation of $x(t)$ and $x(t-1)$ equal to 0.950), though less than the dollar/euro rate (0.999). If $x(t)$ is a random walk, the autocorrelation must be 1 . In econometrics, when this hypothesis is valid, we say that there are unit roots. The classic test for the existence of a unit root is the Dickey-Fuller test, which is based on comparing the regression coefficient of $x(t)$ over $x(t-1)$ with 1 , which is the theoretical value of the random walk. For the dollar/euro rate (and for the other rates examined in this study), the test is inconclusive: it neither proves nor disproves the existence of the unit root.

In contrast, in the series consisting of the deviations of the dollar/euro rate with respect to the trend in Figure 2, the test yields a level of significance below 0.01 . This means we can reject the random walk model and consider this series stationary. The same result is obtained for the other exchange rates. This finding and an exploration using graphs such as Figure 8 suggest that we can examine the short cycle for all the exchange rates considered in this study from one and the same point of view.

For each of these rates, we have fitted a set of ARMA models to the deviations of the rate with respect to a trend obtained by the procedure used in Figure 2. As a first approximation we use an ordering of the different ARIMA models according to the Akaike information criterion (AIC), which guides us in selecting the model.

Overall, the results are fairly consistent. In four cases, the model chosen is the AR(1) model, while in the others the difference between the best model and the AR(1) model seems irrelevant. The exceptions are the Mexican peso, which needs a second AR term, and the rand, which has a more complex autocorrelation structure. If we fit an AR model to all the cases, unifying them, the results of the estimation are very consistent. While for the euro the coefficient is 0.954, for the other rates it ranges between 0.941 and 0.949. Except for the Mexican peso and the rand, the autocorrelation function of the residuals of this model do not invalidate the model.

Thus, we have characterized dollar/euro exchange rate movements by superimposing a short cycle on a long cycle. The long cycle consists of a succession of appreciations and depreciations that are approximately linear functions of time, with fairly well defined turning points which are confirmed by the study of other exchange rates. The short cycle, on the other hand, is reasonably well described by an AR(1) model, with a parameter approximately equal to 0.95 . To complete the description, we shall describe exchange rate behavior on a daily scale by examining the volatility of daily returns.

\section{Daily returns of the dollar/euro rate}

Figure 9 shows the daily log returns of the dollar/euro rate. Here, each return is the daily change of the log of the exchange rate. Except for a few outliers, the returns fluctuate within a band of \pm 0.015 . Examining this question in more detail, we find that $88.5 \%$ of the daily changes in this exchange rate (in absolute value) are less than 1\%, and that $98.0 \%$ are less than $1.5 \%$. These are small values compared with those found in stock market assets.

Table 3 shows a statistical comparison between the returns of the dollar/euro rate and those of some other exchange rates. On the whole, the dollar/euro return statistics are similar to those for the exchange rates of other European currencies (not only those included in this table) and 
the Canadian dollar. The variability is of the same order as was observed in Figure 9, while the asymmetry is very weak (especially in the case of the euro) and the kurtosis is moderate. Needless to say, the kurtosis reveals a greater presence of extreme returns than would be expected from a normal distribution, which is typical in the statistics of financial returns (fat tails). Nevertheless, even these kurtosis values can be considered relatively moderate, as much higher values are quite common in (daily) financial returns. For example, Engle and Patton (2001) cite a kurtosis value of 9.047 for returns of the Dow Jones Industrial Index (from August 1998 to August 2000).

\section{Table 3}

Daily exchange rate returns

\begin{tabular}{lccccc}
\hline & Mean & Deviation & Asymmetry & Kurtosis & Autocorrelation \\
\hline USD/EUR & $0.000 \%$ & $0.632 \%$ & 0.014 & 0.608 & 0.001 \\
USD/GBP & $0.003 \%$ & $0.514 \%$ & -0.083 & 0.518 & 0.020 \\
USD/CHF & $0.002 \%$ & $0.674 \%$ & 0.045 & 0.504 & -0.036 \\
USD/CAD & $0.015 \%$ & $0.450 \%$ & -0.025 & 0.686 & 0.000 \\
USD/MXP & $-0.005 \%$ & $0.497 \%$ & -0.614 & 6.408 & 0.055 \\
USD/SAR & $-0.004 \%$ & $1.054 \%$ & -0.291 & 7.589 & -0.015 \\
USD/JPY & $-0.002 \%$ & $0.646 \%$ & 0.223 & 2.028 & -0.035 \\
USD/AUD & $0.009 \%$ & $0.697 \%$ & -0.505 & 1.911 & 0.029 \\
TWEI & $-0.001 \%$ & $0.254 \%$ & 0.169 & 0.637 & 0.016 \\
\hline
\end{tabular}

The higher kurtosis values of other exchange rates indicate the presence of extreme returns. For example, the kurtosis value of the Mexican peso is due to fluctuations in January 1999 and is corrected by starting the series seven days later. The rand is affected by similar circumstances at the end of 2001. Lastly, the autocorrelation is very low. The Asian countries have less variability of returns.

On the whole, these statistics are compatible with the random walk model for European currencies and the Canadian dollar, with returns showing a slightly leptokurtic distribution, which can be modeled using a $t$ distribution with around 14 degrees of freedom (corresponding to a kurtosis of 0.6). For the Asian and Latin American currencies, the distributions are further from normal.

The autocorrelation coefficients in the table, corresponding to the first-order autocorrelation (correlation between $r(t)$ and $r(t-1)$ ), seem to be consistent with the random walk model, that is, with there being no correlation between the returns of these rates. In econometrics this hypothesis is associated with market efficiency, where no information about the past allows us to make any predictions, as market prices automatically incorporate all information.

Nonetheless, here we applied a conventional test (the Ljung-Box test) to the autocorrelation coefficients (not only the first-order ones) of the returns of these exchange rates. We obtained significant values for all rates except the euro (where, even so, the significance is 0.081). This issue has been debated in the literature, for daily, weekly and monthly returns. Alternatives to the traditional tests have occasionally been tested, focusing on the autocorrelation coefficients, with the aim of detecting deviations in exchange rate returns with respect to the model. For example, Liu and He (1991) discuss the virtues of the variance ratio test for the weekly returns of various exchange rates. 
Although our conclusion here is that for the exchange rates of most free-floating currencies the random walk hypothesis is not valid, the deviations of the model seem irrelevant, despite their academic interest, given that the autocorrelation coefficients rarely exceed 0.05. Accordingly, we shall not insist on this issue, but merely point out that our results contradict the supposed efficiency of the currency market, although we do not consider the deviations relevant from a practical point of view.

\section{Figure 9}

Daily returns of the dollar/euro rate

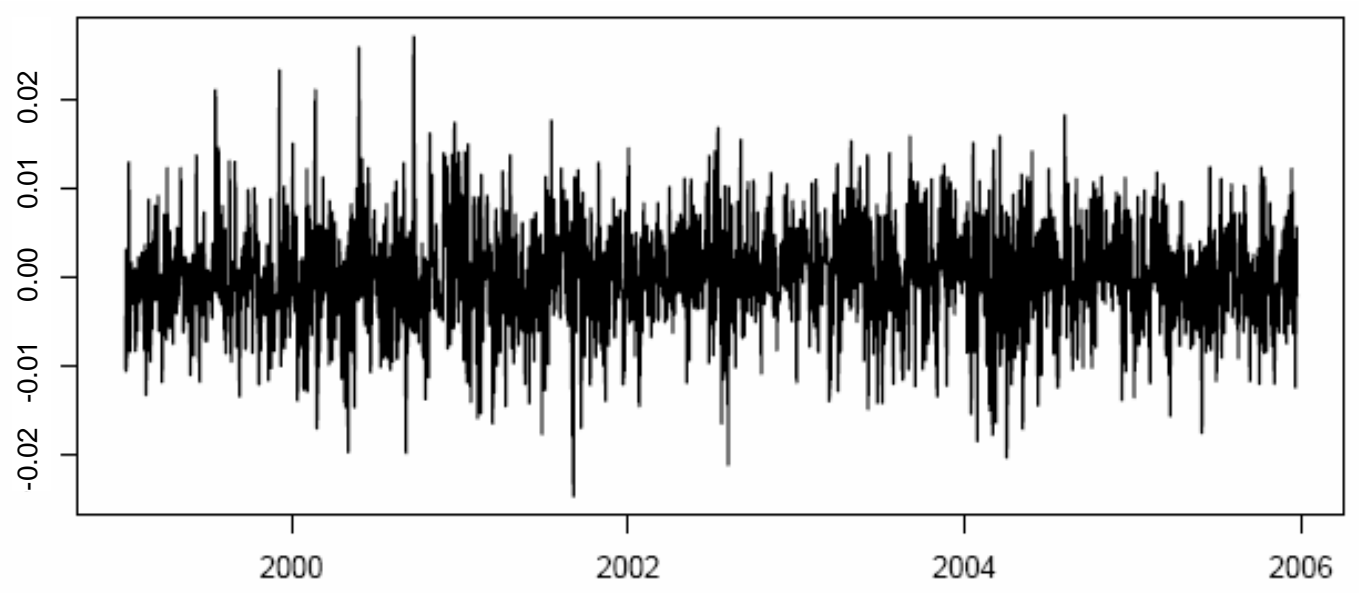

Figure 10 compares the distribution of the returns, the normal distribution, and a Student's $t$ distribution whose number of degrees of freedom has been chosen in accordance with the kurtosis shown in Table 3. We have used a method proposed by Hazelton (2003). The graph shows the normalized returns (dividing by the standard deviation from Table 1), and the density is in $\log$ scale. The line of dots shows the empirical density, smoothed with a Gaussian core (Hazelton's article gives the details and variants of the method). The solid line shows a standard normal density. And the dotted line shows a Student's $t$ distribution, using 14 degrees of freedom for the euro/dollar rate (which gives a kurtosis of 0.6) and 7 degrees of freedom for the U.S. dollar/Australian dollar rate (kurtosis of 2).

On the left, the $t$ distribution fits the euro returns very well, but on the right, the $t$ distribution seems a better fit for the lower tail, while the normal distribution fits the upper tail better. This may be attributed to the asymmetry of the returns distribution. Note that the extreme returns of the lower tail of the right-hand figure correspond to appreciations of the Australian dollar with respect to the U.S. dollar, so that as a result of the asymmetry the extreme appreciations are more pronounced than the extreme depreciations.

Table 4 shows the correlations between the returns of the same exchange rates, which are weaker than the correlations in Table 1, except in the case of the euro, the Swiss franc and the TWEI. We should not overhastily take these correlations as evidence of "influences" exerted by movements in some exchange rates on movements in others. Two variables may be strongly correlated simply because both are influenced by a third variable. Here, that third variable is the value of the dollar. 


\section{Table 4}

Correlation of daily returns

\begin{tabular}{|c|c|c|c|c|c|c|c|c|}
\hline & USD/GBP & USD/CHF & USD/CAD & USD/MXP & USD/SAR & USD/JPY & USD/AUD & TWEI \\
\hline USD/EUR & 0.693 & 0.942 & 0.331 & -0.099 & 0.289 & 0.344 & 0.480 & -0.803 \\
\hline USD/GBP & & 0.688 & 0.273 & -0.053 & 0.271 & 0.330 & 0.427 & -0.668 \\
\hline USD/CHF & & & 0.318 & -0.125 & 0.262 & 0.374 & 0.441 & -0.771 \\
\hline USD/CAD & & & & 0.086 & 0.245 & 0.228 & 0.486 & -0.623 \\
\hline USD/MXP & & & & & 0.125 & -0.033 & 0.082 & -0.199 \\
\hline USD/SAR & & & & & & 0.170 & 0.347 & -0.362 \\
\hline USD/JPY & & & & & & & 0.311 & -0.644 \\
\hline USD/AUD & & & & & & & & -0.618 \\
\hline
\end{tabular}

We may ask ourselves to what extent the correlation between the returns of two of these rates is independent of fluctuations in the exchange value of the dollar. If, as before, we take the TWEI as a proxy for the "intrinsic" value of the dollar, a measure is given by the partial correlation of the returns of the two rates (conditioning the return of the TWEI index).

Figure 10a

Returns of the dollar/euro rate

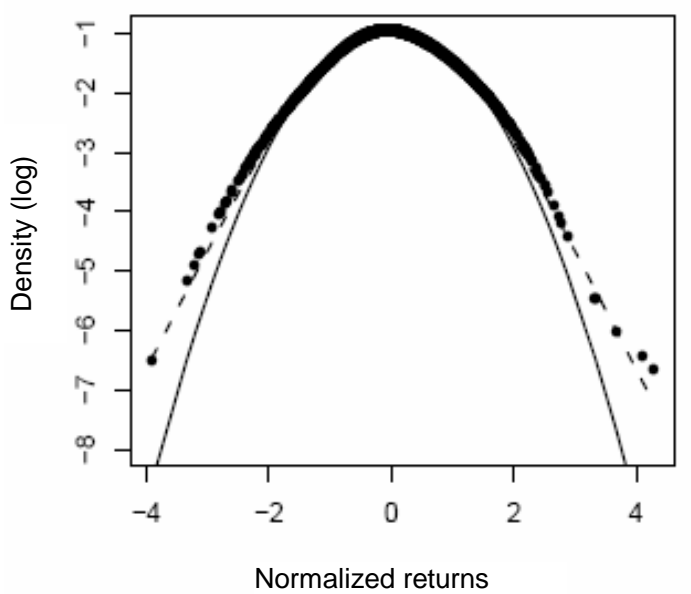

Figure $10 b$

Returns of the US dollar/Australian dollar rate

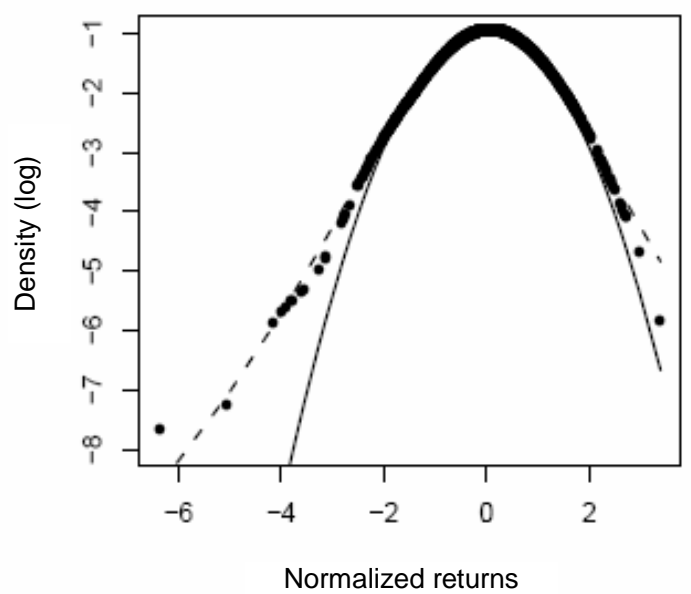

Table 5 shows the partial correlation coefficients of the returns of the dollar/euro rate with the returns of the other exchange rates. The results are curious. The correlation with the Swiss franc remains, and the correlation with the pound is weaker, while the correlation with the rand and the Australian dollar disappears. The coefficients of the Canadian dollar, the Mexican peso and the yen indicate that, once the influence of the exchange value of the U.S. dollar is eliminated, the returns of these rates tend in the opposite direction to those of the dollar/euro rate.

\section{Table 5}

Partial correlation of the daily returns of the dollar/euro rate

\begin{tabular}{ccccccc}
\hline USD/GBP & USD/CHF & USD/CAD & USD/MXP & USD/SAR & USD/JPY & USD/AUD \\
\hline 0.352 & 0.851 & -0.363 & -0.443 & -0.004 & -0.379 & -0.034 \\
\hline
\end{tabular}


Another interesting point with respect to the correlation between the returns of the different exchange rates is how they change over the period studied. To illustrate, Table 6 shows the correlations in four periods, the first three of two years each and the last of one year. These results show all the rates tending in the same direction. The Table 6 results could be taken to suggest that the currency markets became more integrated over this period.

\section{Table 6}

Correlation of the returns of the dollar/euro rate in different periods

\begin{tabular}{lccccc}
\hline & $\mathbf{1 9 9 9 - 2 0 0 0}$ & $\mathbf{2 0 0 1 - 2 0 0 2}$ & $\mathbf{2 0 0 3 - 2 0 0 4}$ & $\mathbf{2 0 0 5}$ & $\mathbf{1 9 9 9 - 2 0 0 5}$ \\
\hline USD/GBP & 0.575 & 0.711 & 0.744 & 0.800 & 0.693 \\
USD/CHF & 0.942 & 0.932 & 0.949 & 0.957 & 0.942 \\
USD/CAD & 0.001 & 0.209 & 0.563 & 0.503 & 0.332 \\
USD/MXP & -0.139 & -0.268 & -0.009 & 0.240 & -0.099 \\
USD/SAR & 0.192 & 0.053 & 0.442 & 0.679 & 0.289 \\
USD/JPY & 0.118 & 0.357 & 0.495 & 0.647 & 0.344 \\
USD/AUD & 0.232 & 0.409 & 0.680 & 0.694 & 0.481 \\
\hline
\end{tabular}

\section{Volatility of daily returns}

In this section we examine changes in the volatility of daily returns of the dollar/euro rate. We define volatility as the conditional standard deviation, that is, the standard deviation of the return distribution $r(t)$, assuming $r(t-1), r(t-2)$, etc. are known. Mathematically:

$$
\sigma_{t}=s d[r(t) \mid r(t-1), r(t-2), \ldots]
$$

Many different methods for estimating this conditional standard deviation have been proposed. Andersen et al. (2005) provide a recent review of most of these methods. Here, following the line taken in earlier sections, we have opted for a simple non-parametric method, which in this case is a moving average of the squared returns, with exponentially decreasing weights. The formula is:

$$
\sigma_{t}^{2}=(1-\theta)\left(r(t-1)^{2}+\theta r(t-2)^{2}+\theta^{2} r(t-3)^{2}+\theta^{3} r(t-4)^{2}+\ldots\right)
$$

This is the most popular algorithm in the non-academic world, having been adopted by J.P. Morgan in their famous RiskMetrics method. Details of the method and recommendations for choosing the value of $\theta$ are to be found in Morgan Guaranty (1996). Here, we have taken $\theta=0.95$.

Figure 11 shows the result of applying this algorithm to the daily returns of the dollar/euro rate. The volatility ranges between $0.4 \%$ and $0.9 \%$, and so may be considered fairly stable. Normalizing the returns, by dividing by the volatility, leaves us with a symmetric distribution with a kurtosis of 0.821 , somewhat higher than that of Table 3. 


\section{Figure 11}

Volatility of the dollar/euro rate

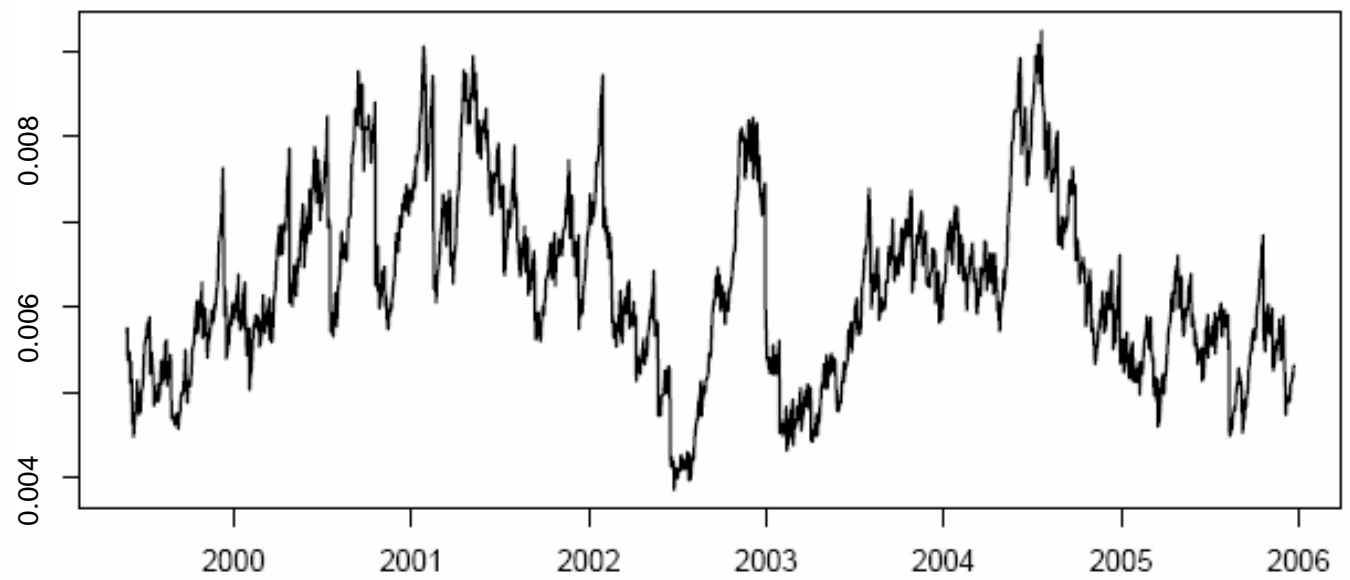

The suitability of the RiskMetrics method in this case is supported by the fact that, in the dollar/euro rate (which again is an exception), we found no evidence of ARCH effects, that is, of autocorrelation in the squared returns. Such effects are usual in financial returns and are the basis of the ARCH model and all its cognates (Andersen et al., 2005).

In Figure 12 we have added 95\% limits to the returns chart from Figure 9. The inner band has been calculated using the normal distribution, with the formula $\pm 1.96 \sigma_{t}$, while for the outer band we have used the $t$ distribution with 11 degrees of freedom (fitted to the kurtosis we found). We have restricted the chart to 2005, a period of very stable volatility, for greater visibility. 6.3\% of the returns fall outside the inner band (normal), while $4.4 \%$ are outside the outer band (Student's).

\section{Figure 12}

95\% limits for the dollar/euro rate






\section{Conclusions}

- In this report we examined dollar/euro exchange rate movements from January 1999 to the end of 2005. These movements were described by superimposing a short cycle, of one to three months, on a long cycle.

- The long cycle can be approximated reasonably well by a segmented linear trend. The short cycle may be characterized by an AR(1) model whose parameter is close to 0.95. This same model was found consistently in all the rates examined.

- We used the Trade Weighted Exchange Index published by the St. Louis Federal Reserve Bank as a proxy for the "intrinsic" exchange value of the dollar. This allowed us to examine the correlations between exchange rates from a new angle.

- We examined the validity of the white noise model for dollar/euro exchange rate returns, but did not find enough evidence in the data to reject it. On the other hand, the model does not pass the conventional tests of autocorrelation coefficients for the other exchange rates considered, although we did not consider the deviations relevant.

- We found the volatility of dollar/euro exchange rate returns to be very stable and relatively low, with no evidence of ARCH effects. 


\section{References}

Andersen, T.G., T. Bollerslev, P.F. Christoffersen and F.X. Diebold (2005), "Volatility forecasting", NBER Working Paper 11188. Published in Handbook of Economic Forecasting, edited by C.W.J. Granger and A. Timmermann, North-Holland.

Andersen, T.G., T. Bollerslev, F.X. Diebold and C. Vega (2002), "Micro effects of macro announcements - Real-time price discovery in foreign exchange”, NBER Working Paper 8959.

Bry, G. and C. Boschan (1971), "Cyclical Analysis of Time Series - Selected Procedures and Computer Programs”, NBER, New York.

Canela, M.A. and E. Pedreira (2006), "La tasa de cambio MXP/USD: Una anomalía estadística”.

Ehrmann, M., M. Fratzscher and R. Rigobon (2005), "Stocks, bonds, money markets and exchange rates - Measuring international financial transmission”, NBER Working Paper 11166.

Engle, R.B. and A.J. Patton (2001), "What good is a volatility model?", Quantitative Finance, 1, pp. 237-245.

Guo, H. and R. Savickas (2005), “Foreign Exchange Rates Don’t Follow a Random Walk”, FMA Annual Meeting, Chicago.

Hazelton, M.L (2003), “A graphical tool for assessing normality”, The American Statistician, 57, pp. 285-288.

Harding, D. and A. Pagan (2002), "Dissecting the cycle - A methodological investigation”, Journal of Monetary Economics, 49, pp. 365-381.

Liu, C.Y. and J. He (1991), "A variance-ratio test of random walks in foreign exchange rates", Journal of Finance, 46, pp. 773-785.

McDermott, C.J. and A. Scott (2000), “Concordance in business cycles”, IMF Working Paper $\mathrm{WP} / 00 / 37$.

Meese, R.A. and K. Rogoff (1983), "Empirical exchange rates of the seventies - Do they fit out of sample?", Journal of International Economics, 14, pp. 3-24.

Morgan Guaranty (1996), “RiskMetrics - Technical Document”, 4th edition, New York.

Sarno, L. (2005), "Towards a solution to the puzzles in exchange rate economics: Where do we stand?”, Warwick Business School, Working Paper. 